\title{
DNA copy number status is a powerful predictor of poor survival in endocrine pancreatic tumor patients
}

\author{
Y M H Jonkers, S M H Claessen, A Perren ${ }^{1}, A M$ Schmitt $^{2}, L \mathrm{~J} \mathrm{Hofland}^{3}$,

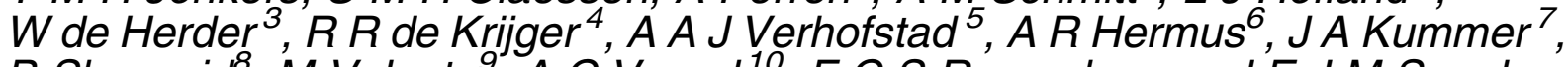 \\ $B$ Skogseid ${ }^{8}, M$ Volante $^{9}, A C$ Voogd $^{10}$, F C S Ramaekers and E J M Speel
}

\author{
Department of Molecular Cell Biology (Box 17), Research Institute for Growth and Development (GROW), University of Maastricht, \\ PO Box 616, 6200 MD Maastricht, The Netherlands \\ ${ }^{1}$ Department of Pathology, Klinikum Rechts der Isar, 81675 Munzh, Germany \\ ${ }^{2}$ Departments of Pathology, Stadtspital Triemli, $\mathrm{CH}-8023$ Zurich, Switzerland \\ ${ }^{3}$ Department of Internal Medicine, section of Endocrinology and ${ }^{4}$ Department of Pathology Erasmus University Medical Center \\ Rotterdam, Rotterdam, The Netherlands \\ Departments of ${ }^{5}$ Pathology and ${ }^{6}$ Endocrinology, Radboud University Medical Center Nijmegen, Nijmegen, The Netherlands \\ ${ }^{7}$ Department of Pathology, University Medical Center Utrecht, Utrecht, The Netherlands \\ ${ }^{8}$ Department of Medical Sciences, University Hospital Uppsala, Uppsala, Sweden \\ ${ }^{9}$ Department of Clinical and Biological Sciences, University of Turin and San Luigi Hospital, Orbassano-Torino, Italy \\ ${ }^{10}$ Department of Epidemiology, University of Maastricht, Maastricht, The Netherlands \\ (Correspondence should be addressed to Y M H Jonkers; Email: y.jonkers@molcelb.unimaas.nl)
}

\begin{abstract}
The clinical behavior of endocrine pancreatic tumors (EPTs) is difficult to predict in the absence of metastases or invasion to adjacent organs. Several markers have been indicated as potential predictors of metastatic disease, such as tumor size $\geq 2 \mathrm{~cm}$, Ki67 proliferative index $\geq 2 \%$, cytokeratin (CK) 19 status, and recently in insulinomas, chromosomal instability (CIN). The goal of this study was to evaluate the value of these markers, and in particular of the $\mathrm{CIN}$, to predict tumor recurrence or progression and tumor-specific death, using a series of 47 insulinomas and 24 noninsulinoma EPTs. From these EPT cases, a genomic profile has been generated and follow-up data have been obtained. The proliferative index has been determined in 68 tumors and a CK19 expression pattern in 50 tumors. Results are statistically analyzed using Kaplan-Meier plots and the log-rank statistic. General CIN, as well as specific chromosomal alterations such as $3 p$ and $6 q$ loss and $12 \mathrm{q}$ gain, turned out to be the most powerful indicators for poor tumor-free survival $(P \leq 0.0004)$ and tumor-specific death $(P \leq 0.0113)$ in insulinomas. The $\mathrm{CIN}$, chromosome $7 \mathrm{q}$ gain, and a proliferative index $\geq 2 \%$ were reliable in predicting a poor tumor-free survival in noninsulinoma EPTs $(P \leq 0.0181$, whereas CK19 expression was the most optimal predictor of tumorspecific death in these tumors. In conclusion, DNA copy number status is the most sensitive and efficient marker of adverse clinical outcome in insulinomas and of potential interest in noninsulinoma EPTs. As a consequence, this marker should be considered as a prognosticator to improve clinical diagnosis, most practically as a simple multi-target test.
\end{abstract}

Endocrine-Related Cancer (2007) 14 769-779

\section{Introduction}

The clinical behavior of endocrine pancreatic tumors (EPTs) is difficult to predict on the basis of their histological features. The presence of metastases is generally accepted to be the only definitive feature of malignancy. Therefore, a reliable classification system is crucial to predict the biological behavior of these tumors. The current WHO classification system is based on expert opinion, but so far its power in large series of individual EPT subtypes with a long-term follow-up remains to be evaluated (Heitz et al. 2004). The classification criteria comprise the presence of metastases, gross invasion, tumor size, percentage of mitoses, proliferative index, and vascular invasion. Tumor resection, the absence of liver and lymph node metastases, and the presence of multiple endocrine 
neoplasia type 1 (MEN1) syndrome appear to be related with a better survival rate (Tomassetti et al. 2005).

Several studies have reported potential biomarkers that are indicators for malignancy of EPTs, such as $\alpha$-chain of human chorionic gonadotropin- $\alpha$ (HCG- $\alpha$ ), cyclooxigenase-2 (COX2), p27 ${ }^{\mathrm{KIP} 1}$, CD99, cytokeratin 19 (CK19), and p53. HCG- $\alpha$ is expressed by $\sim 65 \%$ of malignant functioning EPTs. However, since it is also expressed in benign tumors, this marker is considered to be of limited value (Heitz et al. 1987, Graeme-Cook et al. 1990). Up-regulation of COX2 and CK19, and down-regulation of p27 and CD99 were found to be associated with Ki67 positive, proliferating tumor cells (Canavese et al. 2001, Guo et al. 2001, Ohike \& Morohoshi 2001, Rahman et al. 2003, Goto et al. 2004, Ali et al. 2006). Controversy exists with respect to p53 expression as a marker for malignancy in EPTs. Lee (1996) suggested no role for p53, whereas Pavelic et al. (1995) identified p53 overexpression in all the three cases of malignant insulinomas. We have recently shown that in insulin-producing EPTs, chromosomal instability (CIN), identified by analysis of DNA copy number changes using comparative genomic hybridization (CGH), is an optimal predictor for malignant progression (Jonkers et al. 2005). Ki67, p53, and/or CK19 expression have been found to be associated with malignancy only in a few individual insulinoma cases (Jonkers et al. 2006a).

CK19 is a potential immunomarker described to predict poor survival in EPTs. By comparing classification criteria and CK19 immunostaining in a series of 101 EPTs, it was found that CK19 was the only significant predictor of poor survival (Deshpande et al. 2004). In the study presented here, our aim was to investigate the reliability of DNA copy number alterations, including CIN in comparison with CK19 and other clinical parameters to predict poor survival in EPTs. For this purpose, we have collected follow-up data of 71 EPT patients, including 47 cases of insulinoma.

\section{Materials and methods}

\section{Tumor material and patient data}

Seventy-one EPTs for which a CGH profile was generated (Speel et al. 1999, 2001, Zhao et al. 2001, Jonkers et al. 2005, 2006b) and follow-up data could be obtained, were studied here. They included 47 insulinomas, 6 gastrinomas, 2 glucagonomas, 5 vipomas, and 11 non-functioning tumors. These cases and their corresponding follow-up data were available from the archives of the Departments of Pathology of the University Hospital Zurich, Switzerland, and the University of Torino, Italy, the Department of Medical Sciences, University Hospital Uppsala, Sweden, and the Departments of Pathology of the University Medical Centers of Rotterdam, Utrecht and Nijmegen, The Netherlands (Table 1). Ki67 proliferative index could be determined in 68 tumors and CK19 expression in 50 tumors. The study was done in line with the code 'Proper Secondary Use of Human Tissue' as implemented by the Dutch Federation of Biomedical Scientific Societies. The tumors were classified according to the most recent WHO classification (Heitz et al. 2004). All tumors were not associated with the inherited MEN1 syndrome. The mean age of the 71 EPT patients, including 40 females and 31 males, was 50.6 years (range 5-82 years). Follow-up ranged from 0.6 to 21.5 years (mean 7.3 years). The diameter of the insulinomas ranged from 0.5 to $10 \mathrm{~cm}$ (mean $2.0 \mathrm{~cm}$ ). The diameter of the other functioning EPTs ranged from 2.4 to $8 \mathrm{~cm}$ (mean $4.4 \mathrm{~cm}$ ) and the non-functioning EPTs from 1.2 to $10 \mathrm{~cm}$ (mean $5.8 \mathrm{~cm}$ ).

Twenty-eight of the patients had localized disease at diagnosis as defined by: 1) the absence of extrapancreatic spread of the tumor as evidenced by Computed Tomography, magnetic resonance imaging or ultrasound scanning and 2) a tumor size smaller than $2 \mathrm{~cm}$ in diameter. Nineteen patients had a tumor with uncertain behavior, defined by the absence of extrapancreatic spread of the tumor, but with a tumor size of at least $2 \mathrm{~cm}$ in diameter, angioinvasion or a proliferative index of at least $2 \%$. Twenty-four patients showed metastatic disease at diagnosis.

\section{Detection of CIN by CGH analysis}

CGH was used to analyze genome-wide DNA copy number imbalances in EPTs (Speel et al. 1999, 2001, Zhao et al. 2001, Jonkers et al. 2005, 2006a,b). This approach uses differentially labeled tumor and 'reference' DNA, which are competitively hybridized to normal metaphase chromosomes (conventional $\mathrm{CGH}$ ) or to mapped genomic clones (array $\mathrm{CGH}$ ). The ratio of the fluorescence intensities detected is indicative of the relative DNA copy number in tumor versus reference DNA (Fig. 1A; Kallioniemi et al. 1992, Davies et al. 2005, Pinkel \& Albertson 2005). The array CGH analyses were all performed in Maastricht. The conventional CGH analyses of the non-insulinoma EPTs were performed in Zurich with the same resolution as the conventional CGH performed in Maastricht. 
Table 1 Tumor diagnosis and follow-up status

\begin{tabular}{|c|c|c|c|c|c|c|c|c|}
\hline $\begin{array}{l}\text { Tumor type } \\
\text { and } n r\end{array}$ & $\begin{array}{c}\text { Follow-up } \\
\text { time } \\
\text { (months) }\end{array}$ & $\begin{array}{l}\text { Follow-up } \\
\text { status }\end{array}$ & Diagn. & CIN & Ki67 $\geq 2 \%$ & Size $\geq 2 \mathrm{~cm}$ & $\begin{array}{l}\text { CK19 } \\
\text { positive }\end{array}$ & $\begin{array}{c}\text { Meta } \\
\text { at diagn. }\end{array}$ \\
\hline \multicolumn{9}{|l|}{ Insulinoma } \\
\hline 1 & 216 & AW & B & - & - & - & - & - \\
\hline 2 & 132 & AW & B & - & - & - & - & - \\
\hline 3 & 24 & AW & $\mathrm{B}$ & - & - & - & & - \\
\hline 4 & 252 & AW & B & - & - & - & - & - \\
\hline 5 & 96 & AW & $B$ & - & - & - & & - \\
\hline 6 & 120 & AW & $\mathrm{B}$ & - & - & - & & - \\
\hline 7 & 132 & AW & $B$ & - & - & - & - & - \\
\hline 8 & 12 & AW & $B$ & - & - & - & - & - \\
\hline 9 & 108 & AW & B & - & - & - & & - \\
\hline 10 & 72 & AW & $B$ & - & - & - & & - \\
\hline 11 & 96 & AW & $B$ & - & - & - & & - \\
\hline 12 & 60 & AW & B & - & - & - & & - \\
\hline 13 & 84 & AW & $B$ & - & - & - & - & - \\
\hline 14 & 36 & AW & B & - & - & - & & - \\
\hline 15 & 156 & AW & $B$ & - & - & - & - & - \\
\hline 16 & 84 & AW & $B$ & - & - & - & - & - \\
\hline 17 & 144 & AW & B & - & - & - & - & - \\
\hline 18 & 72 & AW & $B$ & - & - & - & & - \\
\hline 19 & 36 & AW & $B$ & - & - & - & - & - \\
\hline 20 & 72 & AW & B & - & - & - & & - \\
\hline 21 & 168 & AW & $B$ & - & - & - & & - \\
\hline 22 & 48 & AW & B & - & - & - & & - \\
\hline 23 & 24 & AW & B & - & - & - & - & - \\
\hline 24 & 24 & AW & B & + & - & - & - & - \\
\hline 25 & 48 & AW & B & - & - & - & & - \\
\hline 26 & 60 & AW & B & - & + & - & & - \\
\hline 27 & 72 & AW & B & + & - & - & - & - \\
\hline 28 & 96 & AW & UB & + & + & + & & - \\
\hline 29 & 132 & AW & UB & + & - & - & & - \\
\hline 30 & 144 & AW & UB & - & - & + & & - \\
\hline 31 & 84 & AW & UB & + & - & + & & - \\
\hline 32 & 96 & AW & UB & + & - & + & - & - \\
\hline 33 & 216 & AW & UB & + & - & + & - & - \\
\hline 34 & 12 & AW & UB & + & - & + & - & - \\
\hline 35 & 180 & AW & $M$ & + & - & - & - & Meta \\
\hline 36 & 60 & AW & $M$ & + & - & + & - & Meta \\
\hline 37 & 48 & AW & $M$ & + & - & + & - & Meta \\
\hline 38 & 96 & AW & $M$ & - & + & - & - & Meta \\
\hline 39 & 84 & AW & $M$ & - & + & + & - & Meta \\
\hline 40 & 36 & AW & $M$ & + & + & + & - & Meta \\
\hline 41 & 120 & AWD & UB & + & - & + & - & - \\
\hline 42 & 72 & AWD & $\mathrm{M}$ & + & + & + & - & Meta \\
\hline 43 & 120 & AWD & $M$ & + & - & + & + & Meta \\
\hline 44 & 12 & DOD & $M$ & + & - & + & + & Meta \\
\hline 45 & 12 & DOD & $M$ & + & - & - & - & Meta \\
\hline 46 & 12 & DOD & $M$ & + & - & + & & Meta \\
\hline 47 & 24 & DOD & $M$ & + & + & + & - & Meta \\
\hline \multirow{2}{*}{\multicolumn{9}{|c|}{$\begin{array}{l}\text { Non-insulinoma EPTs } \\
\text { Gastrinoma }\end{array}$}} \\
\hline Gastrinoma & & & & & & & & \\
\hline 1 & 8 & AW & UB & - & - & + & - & - \\
\hline 2 & 131 & AW & UB & - & - & + & - & - \\
\hline 3 & 258 & AW & UB & - & - & + & + & - \\
\hline 4 & 46 & AWD & UB & + & + & + & + & - \\
\hline 5 & 123 & AWD & $M$ & + & - & + & + & Meta \\
\hline 6 & 18 & DOD & $M$ & + & + & + & + & Meta \\
\hline
\end{tabular}


Table 1 continued

\begin{tabular}{|c|c|c|c|c|c|c|c|c|}
\hline $\begin{array}{l}\text { Tumor type } \\
\text { and } \mathrm{nr}\end{array}$ & $\begin{array}{c}\text { Follow-up } \\
\text { time } \\
\text { (months) }\end{array}$ & $\begin{array}{l}\text { Follow-up } \\
\text { status }\end{array}$ & Diagn. & CIN & $\mathrm{Ki67} \geq 2 \%$ & Size $\geq 2 \mathrm{~cm}$ & $\begin{array}{l}\text { CK19 } \\
\text { positive }\end{array}$ & $\begin{array}{c}\text { Meta } \\
\text { at diagn. }\end{array}$ \\
\hline \multicolumn{9}{|l|}{ Vipoma } \\
\hline 1 & 162 & AW & M & - & - & & - & Meta \\
\hline 2 & 158 & AWD & UB & + & - & + & - & - \\
\hline 3 & 66 & DOC & $M$ & + & + & + & - & Meta \\
\hline 4 & 99 & DOD & UB & + & - & + & - & - \\
\hline 5 & 58 & DOD & M & - & - & & + & Meta \\
\hline \multicolumn{9}{|l|}{ Glucagonoma } \\
\hline 1 & 79 & DOD & M & + & + & + & + & Meta \\
\hline 2 & 12 & DOD & M & + & & & & Meta \\
\hline \multicolumn{9}{|c|}{ Non-functioning } \\
\hline 1 & 99 & AW & B & - & & - & + & - \\
\hline 2 & 111 & AW & UB & - & - & + & - & - \\
\hline 3 & 108 & AW & UB & - & + & + & - & - \\
\hline 4 & 170 & AWD & UB & + & - & + & - & - \\
\hline 5 & 63 & AWD & UB & + & - & + & + & - \\
\hline 6 & 33 & AWD & UB & + & & + & & - \\
\hline 7 & 96 & AWD & $M$ & + & + & + & - & Meta \\
\hline 8 & 102 & AWD & $M$ & + & + & + & + & Meta \\
\hline 9 & 7 & DOD & $M$ & - & + & + & + & Meta \\
\hline 10 & 72 & DOD & $M$ & + & - & + & + & Meta \\
\hline 11 & 28 & DOD & $M$ & + & + & + & + & Meta \\
\hline
\end{tabular}

Diagn., diagnosis; meta, metastases; B, benign; UB, uncertain behavior; M, malignant; AW, alive without disease; AWD, alive with disease; DOC, dead of other cause; DOD, dead of disease. +, marker present; -, marker absent; empty cell, not analyzed.

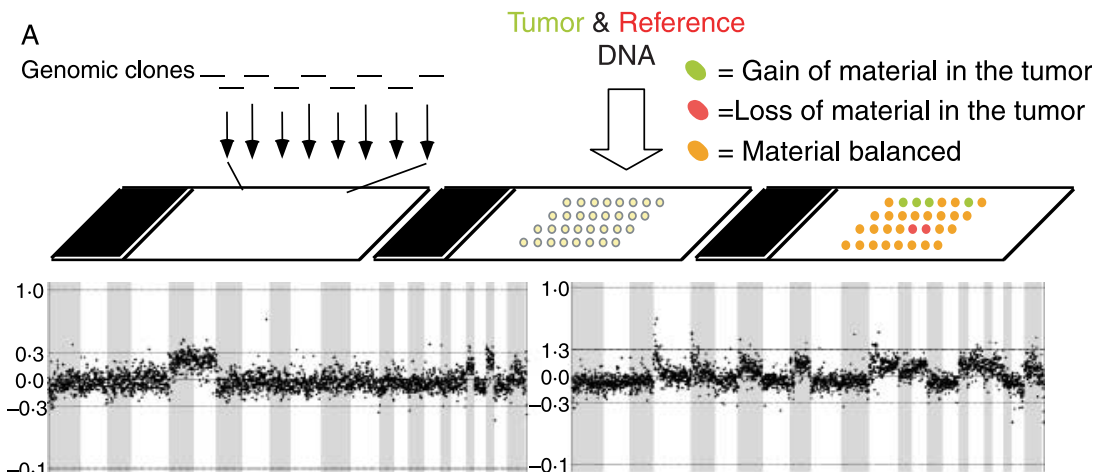

Chromosome1-22, $\mathrm{X}, \mathrm{Y} \rightarrow$

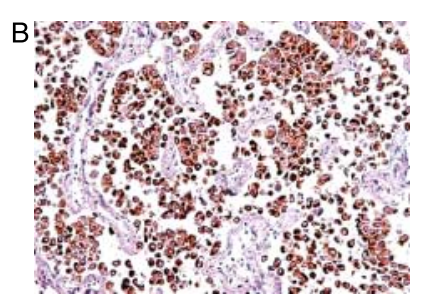

Chromosome1-22, $\mathrm{X}, \mathrm{Y} \rightarrow$

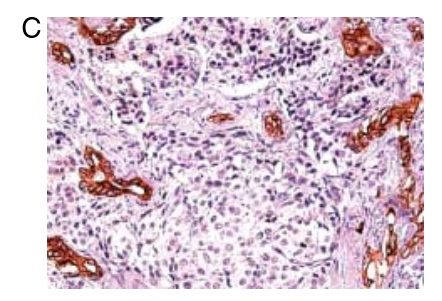

Figure 1 (A) Array CGH procedure with representative examples of array CGH profiles of a benign insulinoma without chromosomal instability (left) and a malignant insulinoma with chromosomal instability (right). Clones are arranged in the order from chromosome 1 to 22 , and $X, Y$ on the $X$-axis. On the $Y$-axis, the $\log _{2}$-transformed tumor over reference DNA values are indicated. Immunohistochemistry for cytokeratin (CK) 19 expression, showing a (B) CK19 positive insulinoma and (C) a CK19 negative insulinoma with positive staining in ductal cells. 
CIN was defined as the presence of at least eight chromosomal aberrations by conventional CGH or 20 aberrations of at least $10 \mathrm{Mb}$ by array CGH (Fig. 1A; Jonkers et al. 2005, 2006a). Sixty-three patient samples were analyzed by conventional CGH, 26 by array $\mathrm{CGH}$, and 18 by both methods. In 16 out of these 18 cases, the results matched based on the criteria described above. In the two other cases CIN was detected by conventional CGH, and 18 aberrations of at least $10 \mathrm{Mb}$ were detected by array CGH. These cases were thus considered to have CIN. Also individual chromosomal alterations were evaluated for their predictive value with respect to metastatic disease or poor survival. Of the chromosomal alterations detected by conventional $\mathrm{CGH}, 97.5 \%$ were also detected by array CGH.

\section{CK19 and Ki67 immunohistochemistry}

CK19 and Ki67 antigen staining was performed on $4 \mu \mathrm{m}$ thick paraffin-embedded tissue sections as described previously (Jonkers et al. 2005, 2006a). Sections were pretreated with $10 \mathrm{mM}$ citrate buffer (pH 6.0) in a microwave oven at $600 \mathrm{~W}$ for $15 \mathrm{~min}$, and incubated with a mouse monoclonal antibody directed against Ki67 (MIB1, 1:100 dilution; DAKO, Glostrup, Denmark) or human CK19 (RCK108, 1:200 dilution, MUbio products BV, Maastricht, The Netherlands) respectively. The primary antibodies were detected by the avidin-biotinylated peroxidase complex protocol (ABC Elite kit, Vector laboratories, Burlingame, CA, USA) and peroxidase activity was visualized using diaminobenzidine (DAB) $/ \mathrm{H}_{2} \mathrm{O}_{2}$ (Sigma Chemical Co). The Ki67 proliferative index was expressed as the percentage of tumor cells that were immunopositive. All tumor cases with cytoplasmic staining for RCK108 in $\geq 5 \%$ of tumor cells were considered CK19 positive (Fig. 1B and C).

\section{Statistical analysis}

For the statistical analyses of the clinical data SPSS software was used (SPSS 12.0.1 software, Chicago, IL, USA). The sensitivity and specificity of each factor for predicting the presence of metastatic disease were calculated. The relationship between different parameters was analyzed using the $\chi^{2}$ or Fisher exact test, as appropriate. The level of significance was defined as $P<0.05$. All factors with statistical significance in a univariate analysis were also included in subsequent multivariate analyses. Survival curves were calculated using the Kaplan-Meier method. The comparison between survival functions for the different factors was assessed with the log-rank statistic.
Tumor-free survival indicated that the patient was still alive, the primary tumor and/or metastases were treated and did not show recurrence and/or progression during follow-up time. When the tumor showed recurrence and/or progression, a patient was designated alive with disease (AWD). Tumor-specific death indicated that the patient died of the disease (DOD) during the follow-up period.

\section{Results}

\section{Parameters to predict metastatic disease Insulinomas}

We examined the reliability of different parameters to predict metastatic disease, including tumor size, Ki67 proliferative index, CK19 expression, CIN, and specific chromosomal aberrations. Table 2 shows that CIN turned out to be the most reliable indicator of metastatic disease with a sensitivity of $85 \%$, followed by $7 \mathrm{q}$ gain and tumor size. Multivariate analysis showed that a combination of CIN and size or size and $6 \mathrm{q}$ loss could increase the sensitivity to $92 \%$. A combination of CIN and Ki67 could even increase this sensitivity to $100 \%$.

\section{Other EPTs}

$\mathrm{CIN}$ also proved to be the only significant parameter to predict metastatic disease in the non-insulinoma EPTs (Table 2). Multivariate analysis showed an increase in sensitivity when combining CIN with Ki67 or CK19 expression, or when combining $3 p$ loss and $7 q$ or $14 q$ gain as markers. Because this tumor group predominantly comprises tumors with a diameter $\geq 2 \mathrm{~cm}$ at presentation, size could not be used as a discriminative predictor for this purpose.

\section{Parameters to predict tumor-free survival and tumor-specific death Insulinomas}

The association between the evaluated parameters and the clinical outcome of insulinomas is presented in Table 3. Tumor recurrence and/or progression or tumor-specific death occurred in a minority of insulinoma patients because of their early presentation usually followed by resection of the tumor. Four insulinoma patients died of disease and three were AWD. Nineteen patients showed CIN including these seven patients. Six out of seven patients with an event had a size larger than $2 \mathrm{~cm}$ in diameter. Only two of these patients showed a Ki67 proliferative index of more than $2 \%$ or CK19 expression. Kaplan-Meier survival analysis underscored the power of CIN and size as significant markers for poor tumor-free survival 
Table 2 Parameters for prediction of metastatic disease in endocrine pancreatic tumors (EPTs)

\begin{tabular}{|c|c|c|c|c|c|}
\hline Insulinomas & Sensitivity $^{\mathrm{a}}(\%)$ & Specificity $^{\mathrm{b}}(\%)$ & OR & $95 \% \mathrm{Cl}$ & $P$ value \\
\hline \multicolumn{6}{|l|}{ Univariate } \\
\hline Size $\geq 2 \mathrm{~cm}$ & 77 & 82 & 15.6 & $3.3-74.2$ & 0.0005 \\
\hline $\mathrm{Ki}-67 \geq 2 \%$ & 39 & 94 & 10.0 & $1.6-61.3$ & 0.0189 \\
\hline CK19 & 17 & 100 & & & NS \\
\hline CIN & 85 & 77 & 17.9 & $3.3-98.1$ & 0.0005 \\
\hline $3 p$ loss & 46 & 91 & 8.9 & $1.8-44.3$ & 0.0126 \\
\hline $6 q$ loss & 54 & 97 & 38.5 & $4.0-372.2$ & 0.0002 \\
\hline $7 q$ gain & 85 & 68 & 11.5 & $2.2-61.0$ & 0.0039 \\
\hline $12 q$ gain & 54 & 85 & 6.8 & $1.6-28.7$ & 0.0174 \\
\hline $14 q$ gain & 62 & 88 & 12.0 & $2.6-55.3$ & 0.0018 \\
\hline \multicolumn{6}{|l|}{ Multivariate } \\
\hline $\mathrm{CIN}$ and/or Ki-67 $\geq 2 \%$ & 100 & 74 & & & 0.0000 \\
\hline $\mathrm{CIN}$ and/or size $\geq 2 \mathrm{~cm}$ & 92 & 74 & 33.3 & $3.8-294.3$ & 0.0002 \\
\hline Size $\geq 2 \mathrm{~cm}$ and/or $6 \mathrm{q}$ loss & 92 & 82 & 56.0 & $6.1-516.8$ & 0.0000 \\
\hline \multicolumn{6}{|l|}{ EPTs excluding insulinomas } \\
\hline \multicolumn{6}{|l|}{ Univariate } \\
\hline Size $\geq 2 \mathrm{~cm}$ & 100 & 13 & & & NS \\
\hline $\mathrm{Ki}-67 \geq 2 \%$ & 53 & 83 & & & NS \\
\hline CK19 & 67 & 71 & & & NS \\
\hline $\mathrm{CIN}$ & 81 & 75 & 13.0 & $1.7-99.4$ & 0.0254 \\
\hline $3 p$ loss & 81 & 63 & & & NS \\
\hline $6 q$ loss & 56 & 63 & & & NS \\
\hline $7 q$ gain & 56 & 75 & & & NS \\
\hline $12 q$ gain & 31 & 88 & & & NS \\
\hline $14 q$ gain & 50 & 88 & & & NS \\
\hline \multicolumn{6}{|l|}{ Multivariate } \\
\hline CIN and/or CK19 & 94 & 50 & 15.0 & $1.3-174.4$ & 0.0506 \\
\hline $\mathrm{CIN}$ and/or $\mathrm{Ki}-67 \geq 2 \%$ & 88 & 63 & 11.7 & $1.5-91.5$ & 0.0390 \\
\hline $3 p$ loss and/or $7 q / 14 q$ gain & 94 & 50 & 15.0 & $1.3-174.4$ & 0.0506 \\
\hline
\end{tabular}

OR, odds ratio; $95 \% \mathrm{Cl}, 95 \%$ confidence interval.

${ }^{\text {a }}$ Percent of the patients with metastases with the parameter.

${ }^{\mathrm{b}}$ Percent of the patients without metastases without the parameter.

in insulinomas, as shown in Table 4 and Fig 2A and B.

The CK19 expression was also shown to be a significant indicator of poor tumor-free survival in insulinomas, although only two out of six insulinomas with an event (one with tumor-specific death and the other with tumor progression) showed a positive CK19 staining. None of the other insulinomas showed expression of CK19.

Also specific chromosomal alterations, including $3 p$ and $6 \mathrm{q}$ loss, and $7 \mathrm{q}, 12 \mathrm{q}$, and $14 \mathrm{q}$ gain were strong parameters for tumor recurrence and/or progression or tumor-specific death in these tumors. Fig $2 \mathrm{C}$ shows the Kaplan-Meier curve for chromosome $6 \mathrm{q}$ loss as the most significant chromosomal marker for poor tumorfree survival. Furthermore, female patients had a significantly better tumor-free and tumor-specific survival when compared with male patients $(P=0.017$ and 0.014 respectively), which is in line with the higher incidence of metastases in male versus female patients (Danforth et al. 1984). Multivariate analysis did not improve significance.

\section{Other EPTs}

Table 4 shows also the parameters for poor tumor-free survival and tumor-specific death in the non-insulinoma EPT patients. CIN proved to be a reliable marker for poor tumor-free survival in these patients, followed by Ki67 proliferative index and chromosome 7q gain (Fig. 2D and E). CK19 was detected as the most significant marker for tumor-specific death because of its positive staining in six out of seven patients with tumor-specific death (Fig. 2F).

\section{Discussion}

In this study, we have examined the value of several proposed indicators of malignancy and clinical outcome in a large group of insulinomas and noninsulinoma EPTs. These parameters include tumor size $\geq 2 \mathrm{~cm}$, Ki67 proliferative index of $\geq 2 \%$, CK19 expression, and chromosomal alterations, including CIN. CIN and specific chromosomal alterations turn out to be reliable indicators for metastatic disease and 
Table 3 Prognostic parameters and the clinical behavior of endocrine pancreatic tumor (EPT) patients

\begin{tabular}{|c|c|c|c|c|}
\hline Type of tumor $(n)$ & AW & DOD & AWD & DOC \\
\hline Insulinomas (47) & 40 & 4 & 3 & 0 \\
\hline Gastrinomas (6) & 3 & 1 & 2 & 0 \\
\hline Glucagonomas (2) & 0 & 2 & 0 & 0 \\
\hline Vipomas (5) & 1 & 2 & 1 & 1 \\
\hline Non-functioning (11) & 3 & 3 & 5 & 0 \\
\hline \multicolumn{5}{|l|}{ Parameter $(n)$} \\
\hline \multicolumn{5}{|l|}{ Insulinomas } \\
\hline \multicolumn{5}{|l|}{ CIN } \\
\hline Present (19) & 12 & 4 & 3 & 0 \\
\hline Absent (28) & 28 & 0 & 0 & 0 \\
\hline \multicolumn{5}{|l|}{ Size } \\
\hline$\geq 2 \mathrm{~cm} \mathrm{(16)}$ & 10 & 3 & 3 & 0 \\
\hline$<2 \mathrm{~cm}(31)$ & 30 & 1 & 0 & 0 \\
\hline \multicolumn{5}{|l|}{ Ki-67 } \\
\hline$\geq 2 \%(7)$ & 5 & 1 & 1 & 0 \\
\hline$<2 \%(40)$ & 35 & 3 & 2 & 0 \\
\hline \multicolumn{5}{|l|}{ CK19 } \\
\hline Positive (2) & 0 & 1 & 1 & 0 \\
\hline Negative (26) & 22 & 2 & 2 & 0 \\
\hline \multicolumn{5}{|c|}{ EPTs excluding insulinomas } \\
\hline \multicolumn{5}{|c|}{ CIN } \\
\hline Present (15) & 0 & 6 & 8 & 1 \\
\hline Absent (9) & 7 & 2 & 0 & 0 \\
\hline \multicolumn{5}{|l|}{ Size } \\
\hline$\geq 2 \mathrm{~cm}(20)$ & 5 & 6 & 8 & 1 \\
\hline$<2 \mathrm{~cm}(1)$ & 1 & 0 & 0 & 0 \\
\hline \multicolumn{5}{|l|}{ Ki-67 } \\
\hline$\geq 2 \%(9)$ & 1 & 4 & 3 & 1 \\
\hline$<2 \%(12)$ & 5 & 3 & 4 & 0 \\
\hline \multicolumn{5}{|l|}{ CK19 } \\
\hline Positive (12) & 2 & 6 & 4 & 0 \\
\hline Negative (10) & 5 & 1 & 3 & 1 \\
\hline
\end{tabular}

AW, alive without disease; DOD, dead of disease; AWD, alive with disease; DOC, dead of other cause.

poor tumor-free survival in insulinoma and noninsulinoma EPTs, and for tumor-specific death in insulinomas. CK19 expression is not a strong prognostic indicator in insulinomas, but is the most optimal indicator of tumor-specific death in the other EPTs.

From previous studies, it has become clear that malignant progression of EPTs is associated with an accumulation of genetic alterations (Speel et al. 1999, 2001, Jonkers et al. 2005, 2006a). CIN is defined as the presence of at least eight chromosomal aberrations detected by conventional CGH or 20 aberrations of at least $10 \mathrm{Mb}$ detected by array CGH (Jonkers et al. 2005, 2006a). Although the underlying mechanism leading to CIN is yet unknown, we have shown here that this parameter can reliably predict clinical outcome in insulinomas, and also metastatic disease as already described before (Jonkers et al. 2005). Although the sensitivity of CIN to predict tumor-
Table 4 Significant parameters for predicting tumor-specific death (DOD) and poor tumor-free survival (DOD+AWD) in endocrine pancreatic tumor (EPT) patients

\begin{tabular}{|c|c|c|c|}
\hline Marker & $P$ value & Marker & $P$ value \\
\hline \multicolumn{4}{|c|}{ Insulinomas $(n=47)$} \\
\hline \multicolumn{2}{|c|}{$\mathrm{DOD}(n=4)$} & \multicolumn{2}{|c|}{$\mathrm{DOD}+\mathrm{AWD}(n=7)$} \\
\hline CIN & 0.0113 & $\mathrm{CIN}$ & 0.0004 \\
\hline $3 p$ loss & 0.0000 & CK19 & 0.0011 \\
\hline $6 q$ loss & 0.0009 & Size & 0.0017 \\
\hline $7 q$ gain & 0.0269 & $3 p$ loss & 0.0000 \\
\hline $12 q$ gain & 0.0003 & $6 q$ loss & 0.0000 \\
\hline \multirow[t]{3}{*}{$14 q$ gain } & 0.0003 & $7 q$ gain & 0.0013 \\
\hline & & $12 q$ gain & 0.0000 \\
\hline & & $14 q$ gain & 0.0013 \\
\hline \multicolumn{4}{|c|}{ EPTs excluding insulinomas $(n=24)$} \\
\hline \multicolumn{2}{|c|}{$\operatorname{DOD}(n=8)$} & \multicolumn{2}{|c|}{$\mathrm{DOD}+\operatorname{AWD}(n=16)$} \\
\hline CK19 & 0.0314 & $\mathrm{CIN}$ & 0.0012 \\
\hline \multirow[t]{2}{*}{$7 q$ gain } & 0.0497 & Ki-67 & 0.0074 \\
\hline & & $7 q$ gain & 0.0181 \\
\hline
\end{tabular}

DOD, dead of disease; AWD, alive with disease.

specific death is high, the specificity is rather low. This is with high probability due to a number of patients presenting with tumors of uncertain or malignant behavior showing CIN of which the tumors have been treated successfully. Also several frequently occurring specific chromosomal aberrations, associated with CIN in insulinomas, are highly effective as prognostic indicators. In particular, loss of chromosome $3 p$ and $6 q$, and gain of $12 q$ prove to be very strong parameters for poor tumor-free survival. This finding underscores previous results by molecular allelotyping providing evidence for association of metastatic progression with chromosome 3p and 6q loss in EPTs (Chung et al. 1997, Hessman et al. 1999, Barghorn et al. 2001a,b, Rigaud et al. 2001, Guo et al. 2002). Among the putative candidate genes is $F A N C D 2$ which plays a role in the repair of DNA damage (Jin et al. 2003). This gene is located on chromosome $3 \mathrm{p} 25$, a critical region of loss in EPTs (Chung et al. 1997). One of the putative tumor suppressor genes on chromosome 6q24 is lost on transformation (LOT), a widely expressed zinc finger protein that inhibits cell growth through induction of apoptotic cell death and G1 arrest. It appears to be epigenetically silenced in different types of cancer, including parathyroid adenomas (Pagotto et al. 2000, Abdollahi et al. 2003).

Large series of individual EPT subtypes other than insulinomas have so far not been studied for the occurrence of CIN. Rigaud et al. (2001) examined a group of 16 non-functioning EPTs by flow cytometry and indicated aneuploidy and Ki67 proliferative index to be the prognostic markers for this tumor subtype. In contrast, Chung et al. (1998) could not identify a 

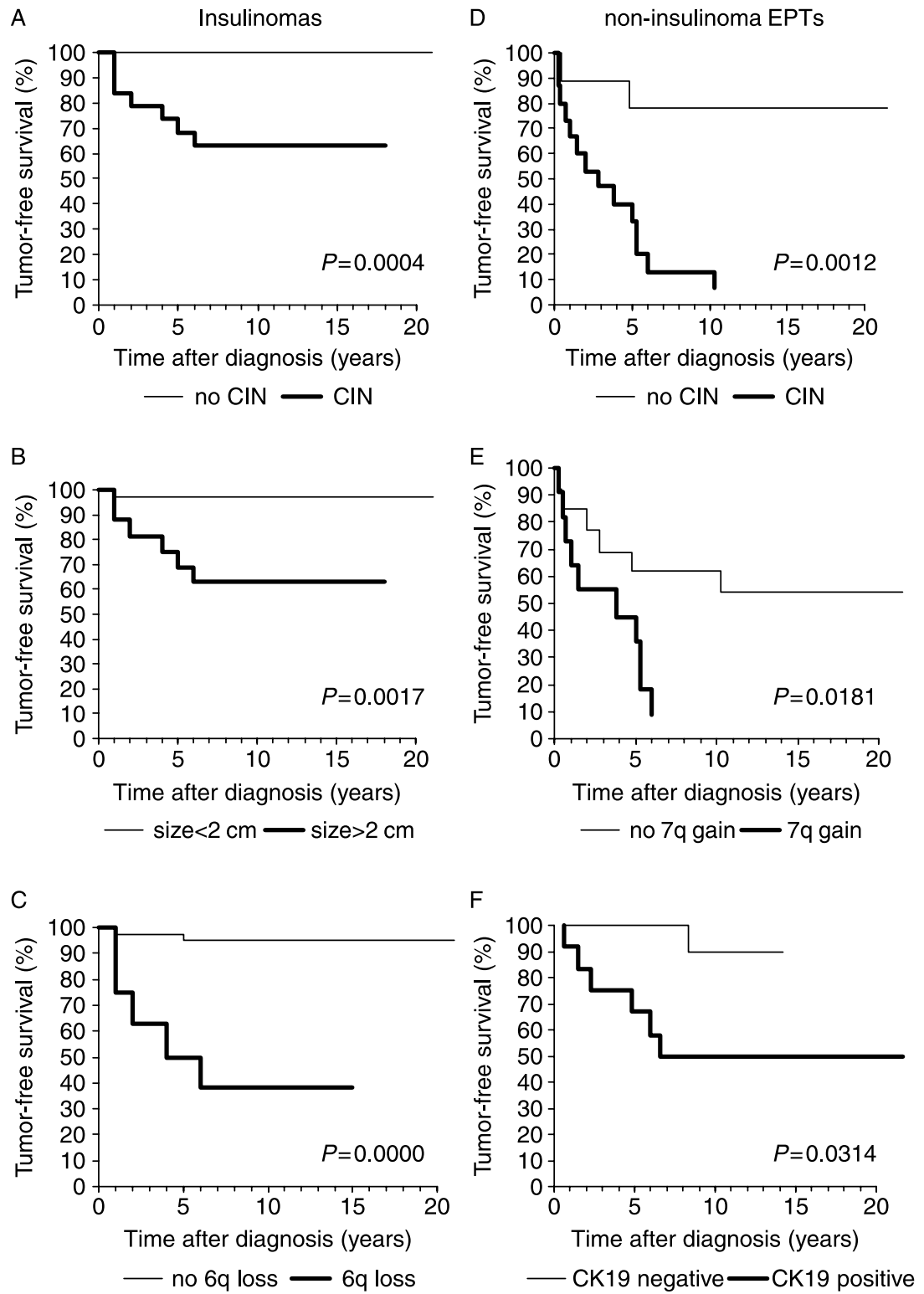

Figure 2 Kaplan-Meier curves correlating tumor-free survival in insulinomas with (A) CIN, (B) tumor size, and (C) chromosome $6 q$ loss; the non-insulinoma EPTs with (D) CIN or (E) chromosome 7q gain, and (F) tumor-specific survival with CK19. Significance scores are indicated.

correlation between frequency of allelic loss and disease stage using genome-wide allelotyping, but this study was hampered by the small groups of individual EPT subtypes. In this study, we have been able to collect follow-up data of 24 non-insulinoma EPTs from which CGH data were available. CIN turned out to be the only significant indicator of metastatic disease and the highest independent predictor of poor tumor-free survival in this group. For the prediction of tumor-specific death, gain of chromosome $7 \mathrm{q}$ and CK19 status were the most reliable markers. It will be essential to further substantiate these findings in larger numbers of individual EPT subtypes in subsequent studies. This is of particular importance because genetic studies indicate differences in genetic make-up in the different EPT subtypes, despite the occurrence of CIN in the malignant tumors (Speel et al. 1999, Heitz et al. 2004).

In a number of cases, the patients with CIN and a poor tumor-free survival or tumor-specific death presented with metastases already at diagnosis. However, one gastrinoma, two vipomas, one 
insulinoma, and three non-functioning tumors without detectable metastases at diagnosis presented with tumor recurrence and/or metastatic progression, or DOD during follow-up time (Table 1). Another patient presenting with CIN in an insulinoma of uncertain behavior also developed metastases after 3 years, but this patient was excluded from this study because of the presence of a MEN1 syndrome. This underscores the reliability of CIN in predicting poor clinical outcome. Therefore, a simplified test to predict CIN will be of value in clinical diagnosis of these tumors. Detection of CIN might change patient management, e.g. by intensifying clinical follow-up. In addition, it may help in directing tumor surgery.

As stated above, CK19 expression proved to be the most optimal marker for tumor-specific death in noninsulinoma EPTs. These data are in accordance with the data of Deshpande et al. (2004) and a recent study by Schmitt et al. (2007), investigating large series of EPTs, including different subtypes. Our data in this study, however, strongly indicate that CK19 expression is a suboptimal marker for poor tumorfree survival in insulinomas. This is probably the consequence of the low percentage of malignant tumors with CK19 immunostaining, as also reported by Ali et al. (2006) and in one of our previous studies (Jonkers et al. 2006a). So far, only one study was unable to correlate CK19 expression with malignancy in EPTs (Albarello et al. 2004). A reason for the discrepancy between these studies could be the use of different CK19-directed monoclonal antibodies and/or criteria for evaluation of immunostaining results. We have used the RCK108 clone, which is used by the most other studies and shown to be more reliable for CK19 analysis than the BA17 clone (La Rosa et al. 2005).

Of the clinicopathological criteria used in the WHO classification, tumor size proved to be a very simple and reliable clinical marker for metastatic disease and poor tumor-free survival in insulinomas. Although CIN appeared to be a more significant parameter than tumor size to predict tumor outcome, the latter parameter is very useful as a result of the early diagnosis of insulinomas and often successful treatment. The Ki67 proliferative index is often $<2 \%$ in insulinomas, and is therefore not a significant marker for poor tumor-free survival in insulinomas. In combination with CIN, however, Ki67 is very useful for predicting metastatic disease in insulinomas and both metastatic disease and poor tumor-free survival in non-insulinoma EPTs. In general, the majority of EPTs are well differentiated according to the most recent WHO classification. In this study, only one insulinoma and one glucagonoma were classified as poorly differentiated with a Ki67 proliferative index of $>10$ mitoses per 10 high-power fields. The respective patients both DOD, thus underscoring a poor tumor-specific survival for patients with poorly differentiated tumors.

In the non-insulinoma EPTs size cannot be efficiently used to discriminate between benign and malignant tumors, because the tumor diameter is usually larger than $2 \mathrm{~cm}$, as also found in this study. However, size $\geq 2 \mathrm{~cm}$ has been described as a predictable marker, because most studies consider EPTs as one group, with the smaller tumors being predominantly benign insulinomas and the larger ones generally comprising the non-insulinoma EPTs with a more malignant behavior (Speel et al. 1999, Schindl et al. 2000, Ohike \& Morohoshi 2005).

In summary, we have identified CIN as well as specific chromosomal alterations as the most reliable indicators of metastatic disease and poor tumor-free survival in all insulinoma and non-insulinoma EPTs, and for tumor-specific death in insulinomas. CK19 expression is the most optimal indicator of tumorspecific death in the non-insulinoma EPTs. Tumor size is particularly powerful as a predictor of metastatic disease in insulinomas. The implementation of these parameters in diagnostic protocols will make the prediction of the clinical behavior of EPTs more accurate.

\section{Acknowledgements}

The authors declare that there is no conflict of interest that would prejudice the impartiality of this scientific work.

\section{References}

Abdollahi A, Pisarcik D, Roberts D, Weinstein J, Cairns P \& Hamilton TC 2003 LOT1(PLAGL1/ZAC1), the candidate tumor suppressor gene at chromosome 6q24-25, is epigenetically regulated in cancer. Journal of Biological Chemistry 278 6041-6049.

Albarello L, Capitanio V, Zerbi A, Di Carlo V \& Doglioni C 2004 Cytokeratin 19 expression in pancreatic endocrine tumors. Journal of the Pancreas 6514.

Ali A, Serra S, Asa SL \& Chetty R 2006 The predictive value of CK19 and CD99 in pancreatic endocrine tumors. American Journal of Surgical Pathology 30 1588-1594.

Barghorn A, Komminoth P, Bachmann D, Rütimann K, Saremaslani P, Mulatta-Feurer S, Perren A, Roth J, Heitz PU \& Speel EJM 2001a Deletion at 3p25.3-p23 is frequently encountered in endocrine pancreatic tumors and is associated with metastatic progression. Journal of Pathology 94 451-458. 
Barghorn A, Speel EJM, Farspour B, Saremaslani P, Schmid S, Perren A, Roth J, Heitz PU \& Komminoth P $2001 b$ Putative tumor suppressor loci at $6 \mathrm{q} 22$ and $6 \mathrm{q} 23-\mathrm{q} 24$ are involved in the malignant progression of sporadic endocrine pancreatic tumors. American Journal of Pathology 158 1903-1911.

Canavese G, Azzoni C, Pizzi S, Corleto VD, Pasquali C, Davoli C, Crafa P, Delle Fave G \& Bordi C 2001 P27: a potential main inhibitor of cell proliferation in digestive endocrine tumors but not a marker of benign behavior. Human Pathology 32 1094-1101.

Chung DC, Smith AP, Louis DN, Graeme-Cook F, Warshaw AL \& Arnold AA 1997 Novel pancreatic endocrine tumor suppressor gene locus on chromosome $3 p$ with clinical prognostic implications. Journal of Clinical Investigation 100 404-410.

Chung DC, Brown SB, Graeme-Cook F, Tillotson LG, Warshaw AL, Jensen RT \& Arnold A 1998 Localization of putative tumor suppressor loci by genome-wide allelotyping in human pancreatic endocrine tumors. Cancer Research 58 3706-3711.

Danforth DN, Gorden P \& Brennan MF 1984 Metastatic insulin-secreting carcinoma of the pancreas: clinical course and the role of surgery. Surgery 96 1027-1037.

Davies JJ, Wilson IM \& Lam WL 2005 Array CGH technologies and their applications to cancer genomes. Chromosome Research 13 237-248.

Deshpande V, Fernandez-del Castillo C, Muzikansky A, Deshpande A, Zukerberg L, Warshaw AL \& Lauwers GY 2004 Cytokeratin 19 is a powerful predictor of survival in pancreatic endocrine tumors. American Journal of Surgical Pathology 28 1145-1153.

Goto A, Niki T, Terado Y, Fukushima J \& Fukayama M 2004 Prevalence of CD99 protein expression in pancreatic endocrine tumors (PETs). Histopathology 45 384-392.

Graeme-Cook F, Bell DA, Flotte TJ, Preffer F, Pastel-Levy C, Nardi G \& Compton C 1990 Aneuploidy in pancreatic insulinomas does not predict malignancy. Cancer 66 2365-2368.

Guo SS, Wu X, Shimoide AT, Wong J \& Sawicki MP 2001 Anomalous overexpression of p27(Kip1) in sporadic pancreatic endocrine tumors. Journal of Surgical Research 96 284-288.

Guo SS, Arora C, Shimoide AT \& Sawicki MP 2002 Frequent deletion of chromosome 3 in malignant sporadic pancreatic endocrine tumors. Molecular and Cellular Endocrinology 190 109-114.

Heitz PU, von Herbay G, Klöppel G, Komminoth P, Kasper M, Höfler H, Muller KM \& Oberholzer M 1987 The expression of subunits of human chorionic gonadotropin (hCG) by nontrophoblastic, nonendocrine, and endocrine tumors. American Journal of Clinical Pathology $\mathbf{8 8}$ 467-472.

Heitz PU, Komminoth P, Perren A, Klimstra DS \& Dayal Y 2004 Tumours of the endocrine pancreas. In Pathology,
Genetics. Tumours of Endocrine Organs, pp 177-208. Eds RA DeLellis, RV Lloyd, PU Heitz \& C Eng. Lyon: IARC Press.

Hessman O, Lindberg D, Einarsson A, Lillhager P, Carling T, Grimelius L, Eriksson B, Akerström G, Westin G \& Skogseid B 1999 Genetic alterations on 3p, 11q13, and $18 \mathrm{q}$ in nonfamilial and MEN1-associated pancreatic endocrine tumors. Genes, Chromosomes and Cancer 26 258-264.

Jin S, Mao H, Schnepp RW, Sykes SM, Silva AC, D'Andrea AD \& Hua X 2003 Menin associates with FANCD2, a protein involved in repair of DNA damage. Cancer Research 63 4204-4210.

Jonkers YMH, Claessen SMH, Perren A, Schmid S, Komminoth P, Verhofstad AA, Hofland LJ, de Krijger RR, Slootweg PJ, Ramaekers FCS et al. 2005

Chromosomal instability predicts metastatic disease in patients with insulinomas. Endocrine-Related Cancer 12 435-447.

Jonkers YMH, Claessen SMH, Veltman JA, Geurts van Kessel A, Dinjens WNM, Skogseid B, Ramaekers FCS \& Speel EJM $2006 a$ Molecular parameters associated with insulinoma progression: chromosomal instability versus p53 and CK19 status. Cytogenetic and Genome Research 115 289-297.

Jonkers YMH, Claessen SMH, Feuth T, Geurts van Kessel A, Ramaekers FCS, Veltman JA \& Speel EJM $2006 b$ Novel candidate tumor suppressor gene loci on chromosomes 11q23-24 and 22q13 involved in human insulinoma tumorigenesis. Journal of Pathology 210 450-458.

Kallioniemi A, Kallioniemi OP, Sudar D, Rutovitz D, Gray JW, Waldman F \& Pinkel D 1992 Comparative genomic hybridization for molecular cytogenetic analysis of solid tumors. Science 258 818-821.

La Rosa S, Bianchi V, Rigoli E, Uccella S \& Capella C 2005 The prognostic significance of cytokeratin 19 expression in pancreatic endocrine tumors (PETs). Virchows Archive 447188.

Lee CS 1996 Lack of p53 immunoreactivity in pancreatic endocrine tumors. Pathology 28 139-141.

Ohike N \& Morohoshi T 2001 Immunohistochemical analysis of cyclooxygenase (COX)-2 expression in pancreatic endocrine tumors: association with tumor progression and proliferation. Pathology International 51 770-777.

Ohike N \& Morohoshi T 2005 Pathological assessment of pancreatic endocrine tumors for metastatic potential and clinical prognosis. Endocrine Pathology 16 33-40.

Pagotto U, Arzberger T, Theodoropoulou M, Grubler Y, Pantaloni C, Saeger W, Losa M, Journot L, Stalla GK \& Spengler D 2000 The expression of the antiproliferative gene $Z A C$ is lost or highly reduced in non-functioning pituitary adenomas. Cancer Research $606794-6799$. 
Pavelic K, Hrascan R, Kapitanovic S, Karapandza N, Vranes Z, Belicza M, Kruslin B \& Cabrijan T 1995 Multiple genetic alterations in malignant metastatic insulinomas. Journal of Pathology 177 395-400.

Pinkel D \& Albertson DG 2005 Array comparative genomic hybridization and its applications in cancer. Nature Genetics 37 11-17.

Rahman A, Maitra A, Ashfaq R, Yeo CJ, Cameron JL \& Hansel DE 2003 Loss of p27 nuclear expression in a prognostically favorable subset of well-differentiated pancreatic endocrine neoplasms. American Journal of Clinical Pathology 120 685-690.

Rigaud G, Missiaglia E, Moore PS, Zamboni G, Falconi M, Talamini G, Pesci A, Baron A, Lissandrini D, Rindi G et al. 2001 High resolution allelotype of nonfunctional pancreatic endocrine tumors: identification of two molecular subgroups with clinical implications. Cancer Research 61 285-292.

Schindl M, Kaczirek K, Kaserer K \& Niederle B 2000 Is the new classification of neuroendocrine pancreatic tumors of clinical help? World Journal of Surgery 24 1312-1318.

Schmitt AM, Anlauf M, Rousson V, Schmid S, Kofler A, Riniker F, Bauersfeld J, Barghorn A, Probst N, Moch H et al 2007 WHO 2004 criteria and CK19 are reliable prognostic markers in pancreatic endocrine tumors. American Journal of Surgical Pathology [in press]

Speel EJM, Richter J, Moch H, Egenter C, Saremaslani P, Rütimann K, Zhao J, Barghorn A, Roth J, Heitz PU et al. 1999 Genetic differences in endocrine pancreatic tumor subtypes detected by comparative genomic hybridization. American Journal of Pathology 155 1787-1794.

Speel EJM, Scheidweiler AF, Zhao J, Matter C, Saremaslani P, Roth J, Heitz PU \& Komminoth P 2001 Genetic evidence for early divergence of small functioning and nonfunctioning endocrine pancreatic tumors: gain of 9q34 is an early event in insulinomas. Cancer Research 61 5186-5192.

Tomassetti P, Campana D, Piscitelli L, Casadei R, Santini D, Nori F, Morselli-Labate AM, Pezzilli R \& Corinaldesi R 2005 Endocrine pancreatic tumors: factors correlated with survival. Annals of Oncology 16 1806-1810.

Zhao J, Moch H, Scheidweiler AF, Baer A, Schäffer AA, Speel EJM, Roth J, Heitz PU \& Komminoth P 2001 Genomic imbalances in the progression of endocrine pancreatic tumors. Genes, Chromosomes and Cancer 32 364-372. 